\title{
PESQUISA E QUANTIFICAÇÃO DE LISTERIA SP. EM CARCAÇAS SUÍNAS ANTES E APÓS O PROCESSO DE RESFRIAMENTO EM CÂMARA FRIA
}

\author{
Tatiane Sarmento Martins ${ }^{1}$, Roberto Degenhardt², André Thaler ${ }^{1}$, Karine Dalmina ${ }^{1}$, \\ Fernanda Melo ${ }^{1}$, Sandra Maria Ferraz ${ }^{1}$
}

\author{
1 UDESC \\ 2 UNOESC \\ Correspondência: Tatiane Sarmento Martins: tati_martins@hotmail.com
}

RESUMO: A Listeria monocytogenes tem sido reconhecido como um importante patógeno transmitido por alimentos, em decorrência de vários surtos de listeriose. Esta bactéria tem ainda a capacidade de sobreviver em condições adversas de temperatura e $\mathrm{pH}$ e a detecção de células estressadas em alimentos é importante, pois injúrias sub-letais às células podem provocar aumento de sua patogenicidade. $\mathrm{O}$ objetivo deste trabalho é determinar e quantificar a presença de Listeria monocytogenes em carcaças suínas antes e após a câmara fria. As coletas de amostras foram realizadas em um frigorífico localizado no Estado de Santa Catarina. Foram coletadas 226 amostras de carcaças. Foram utilizadas esponjas para a coleta das amostras em quatro pontos de $100 \mathrm{~cm}^{2}$ nas carcaças, totalizando uma área de $400 \mathrm{~cm}^{2}$. Os pontos de coleta foram no pernil, lombo, barriga e papada. No laboratório, as amostras foram acrescidas de $100 \mathrm{~mL}$ de caldo de pré-enriquecimento UVM e homogeneizadas no caldo. $\mathrm{O}$ caldo foi incubado a $30^{\circ} \mathrm{C} / 24 \mathrm{~h}$ e posteriormente repicado 0,1 $\mathrm{mL}$ da cultura para o caldo Fraser, e incubado a $36^{\circ} \mathrm{C} / 24 \mathrm{~h}$. As amostras presuntivamente positivas foram repicadas para Ágar ALOA para isolamento $\left(36^{\circ} \mathrm{C} / 24 \mathrm{~h}\right)$. As colônias suspeitas foram identificadas por meio de provas bioquímicas e CAMP-teste. Para a quantificação foi utilizada a técnica de Número Mais Provável em série de 10 tubos. Das amostras analisadas, 0,44\% (1) foram positivas para Listeria monocytogenes antes e após o processo de resfriamento. O gênero Listeria sp. foi isolado em $10,62 \%$ (12/113) das carcaças que entraram para o resfriamento em câmara fria, sendo a $L$. innocua a mais frequente. Já na saída da câmara fria 30,97\% (35/113) das carcaças foram positivas para Listeria sp. O aumento de carcaças suínas positivas para Listeria sp. após o tratamento térmico, considerando-se a câmara fria, portanto, um ponto de contaminação.

Palavras-chave: abatedouro; contaminação; Listeria sp.; suinocultura

\section{SEARCH AND QUANTIFICATION OF LISTERIA SP. IN PIG CARCASSES BEFORE AND AFTER THE COOLING PROCESS IN COOL CHAMBER}

\begin{abstract}
Listeria monocytogenes has been recognized as an important pathogen transmitted by food, due to several outbreaks of listeriosis. This bacterium also has the ability to survive under adverse conditions of temperature and $\mathrm{pH}$ and the detection of stressed cells in foods is important because sub-lethal cell injury may lead to increased pathogenicity. The objective of this study is to determine and quantify the presence of Listeria monocytogenes in pig carcasses before and after the cool chamber. Material sampling was carried out at one processing plant located in the State of Santa Catarina. 226 samples were collected from carcasses. Sampling was performed by means of sponge and the smear sampling area which covered a defined area of $100 \mathrm{~cm}^{2}$ per sampling, totaling an area of $400 \mathrm{~cm}^{2}$. The points were in the ham, loin, belly and jowl. At the laboratory, samples were added to $100 \mathrm{ml}$ of pre-enrichment broth UVM (University of Vermont) and homogenized in the broth. The broth was incubated at $30^{\circ} \mathrm{C} / 24 \mathrm{~h}$ and subsequently peaked $0.1 \mathrm{ml}$ of culture to Fraser broth and incubated at $36^{\circ} \mathrm{C} / 24 \mathrm{~h}$. The samples presumptively positive were peaked for ALOA Agar for isolation (incubation at $36^{\circ} \mathrm{C} / 24 \mathrm{~h}$ ). The suspected colonies were identified by biochemical tests and testCAMP. For quantification we used the technique of Most Probable Number. From the samples analyzed within the establishments A, $0.44 \%$ (1/226) samples were positive for L. monocytogene. An increase of positive results for Listeria sp. was found on the pig carcases after passing the cold chamber. In this sense, it could be considered a contamination point. The genus Listeria sp. was isolated in $10.62 \%(12 / 113)$ of carcasses that went for cooling in a cold chamber, with an L. innocua more frequent. Have the output from the chamber $30.97 \%$ (35/113) of carcasses were positive for Listeria sp. The increase in positive swine carcasses for Listeria sp. After the heat treatment, considering the cold room, so a point of contamination.
\end{abstract}

Key Words: contamination; slaughterhouse; Listeria sp.; swine production 


\section{INTRODUÇÃO}

Estudos da legislação brasileira e dos requisitos internacionais a respeito da higiene dos produtos de origem animal, sinalizam a necessidade de direcionar ações a todos os segmentos da cadeia produtiva da carne suína, visando à proteção da saúde humana.

Segundo a Organização Mundial da Saúde (OMS, 2007), tem sido um grande desafio adequar a produção de alimentos à demanda crescente da população nas últimas décadas, tornando a alimentação um motivo de preocupação mundial, principalmente nos países em desenvolvimento, que abrigam milhares de pessoas carentes.

Os problemas relativos à contaminação de alimentos para consumo humano tornaram-se mais evidentes com a globalização. A facilidade de distribuição de alimentos industrializados pelo mundo e a livre importação de produtos são exemplos típicos, sendo um fator contribuinte para sua contaminação e, consequentemente, para a ocorrência de danos à saúde humana (BALBANI; BUTUGAN, 2001).

A crescente incidência de toxinfecções alimentares e agravos à saúde estão relacionados a diversos outros fatores, como a modificação no estilo de vida e hábitos alimentares dos consumidores; alterações nas práticas de produção, distribuição, armazenagem e preparo dos alimentos; adaptação dos micro-organismos frente às adversidades ambientais; uso indiscriminado de antimicrobianos; e maior facilidade de diagnóstico das doenças de origem alimentar devido à evolução tecnológica, entre outros (POTES, 2007).

A comunidade científica e o complexo agroindustrial estão trabalhando para melhorar a eficiência na produção de carne e atender as exigências crescentes do mercado consumidor. A competitividade é demonstrada principalmente pelo mercado internacional, que direcionou os investimentos da cadeia produtiva da carne suína para a segurança alimentar (SILVEIRA, 2011).

Atualmente, entre os agentes infeciosos de maior interesse para a saúde pública está a Listeria monocytogenes, bactéria responsável por alto índice de mortalidade em populações de risco, como pacientes imunocomprometidos, idosos e gestantes (OMS, 2007). Por isso, os programas de higiene na indústria devem incluir medidas para garantir a máxima segurança dos alimentos. Políticas e ações destinadas a este fim devem abranger toda a cadeia de produção de alimentos, desde a produção primária até o consumidor final. $\mathrm{Na}$ cadeia produtiva da carne suína, o controle de processo deve assegurar uma abordagem preventiva, para evitar que a L. monocytogenes se torne risco à saúde pública e uma barreira às comercializações.

Devido à importância da $L$. monocytogenes como um agente patogênico de origem alimentar, a maioria dos estudos sobre a Listeria no ambiente tem se concentrado no processamento de alimento em ambientes agrícolas (LOU; YOUSEF, 1999).

Os alimentos são importantes vetores na disseminação da Listeria monocytogenes. Devido à sua ampla distribuição, alimentos como vegetais, leites, queijos, peixes e carnes são facilmente contaminados (BAHRANIMOUGEOT; DONNENBERG, 2004). ILSI (2005) e Rocourt (1999), consideram que os alimentos de maior risco para transmissão de listeriose são os prontos para o consumo e que têm vida de prateleira longa em temperatura de refrigeração.

Korsak e outros (2005), avaliando patógenos causadores de doenças de 
origem alimentar, detectaram a presença de $L$. monocytogenes na superfície de carcaças suínas e reafirmaram que o referido patógeno é um dos principais perigos para a saúde pública. Segundo Jay (2005), foi relatada a contagem elevada de $L$. monocytogenes por grama na pele suína crua $\left(4,3 \times 10^{4}\right)$, nos EUA, em 1991. Casos comprovados de surtos de listeriose de origem alimentar foram relatados na Itália (1990) e França (1993), tendo como principal fonte de infecção linguiça suína e suíno fatiado, respectivamente.

Em estudo realizado por Sakate e outros (2003), o processo de fabricação dos produtos cárneos fermentados, considerados prontos para consumo, não elimina eventual presença de células de $L$. monocytogenes. Neste estudo foram encontradas populações deste micro-organismos em $6,7 \%$ das amostras analisadas.

Nos Estados Unidos, em um período de mais de 39 meses, $7,1 \%$ das 1.727 amostras de carne de gado crua foram positivas para $L$. monocytogenes e, em um período de mais de 21 meses, $19,3 \%$ de 3.700 amostras de frango foram positivas. No mesmo estudo, $2,8 \%$ de diversas carnes prontas para o consumo, provenientes de 4.105 plantas de processamento nos EUA, foram possitivas para os microrganismos (JAY, 2005).

A existência de grupos de risco, associada ao fato de o micro-organismo ser passível de isolamento em alimentos processados, do tipo "pronto para consumo" ou refrigerados, tem despertado o interesse de indústrias alimentícias, autoridades de Saúde Pública e de pesquisadores em vários países (LOGUERCIO et al., 2001).

Nos últimos 10 anos, na França, os produtos de origem suína se mostraram mais frequentemente envolvidos em surtos de listeriose do que os produtos derivados do leite, ressaltando a importância de mais pesquisas buscando a presença de $L$. monocytogenes em produtos cárneos (LECLERC et al., 2002). Lou e Yousef (1999) relatam que surtos de listerioses são frequentemente associados com falhas operacionais ou processamento.

Dessa forma, inúmeras publicações têm tido como objetivo o estudo de $L$. monocytogenes em ambientes de processamento (FENLON; WILSON; DONACHIE, 1996; KORNACHI et al., 2005).

De acordo com a FDA (2003), a L. monocytogenes está disseminada no ambiente e, por isso, pode ser introduzida em instalações de processamento pelos manipuladores, equipamentos, utensílios, instalações e matérias-primas.

$\begin{array}{ccr}\text { Este } & \text { micro-organismo } & \text { pode } \\ \text { multiplicar-se } & \text { lentamente } & \text { em }\end{array}$
temperaturas de refrigeração, assim, desafiando uma importante defesa contra patógenos de origem alimentar: a refrigeração (USDA/FSIS, 2001).

O Departamento de Agricultura dos Estados Unidos e o Serviço de Segurança e Inspeção Alimentar (USDA/FSIS) apontaram $0 \quad L$. monocytogenes como responsável por $50 \%$ (31 de 62) dos recalls para produtos cárneos prontos para 0 consumo (USDA/FSIS, 2001).

Muitos relatos indicam que a $L$. monocytogenes e a $L$. innocua representam ser as mais comuns em ambientes naturais, comparadas com as demais espécies (MACGOWAN et al., 1994). A causa da contaminação de produtos prontos para o consumo por Listeria monocytogenes são as condições sanitárias inadequadas de processamento (FDA, 2003). Além disso, a eliminação total da $L$. monocytogenes em alimentos é difícil porque muitos animais podem ser portadores dessa bactéria (DEDIOL et al., 2002). 

resfriamento em câmara fria

A detecção de L. monocytogenes na linha do abate de suíno dá subsídios para uma análise de perigos criteriosa e, a partir dessa, os pontos críticos de controle podem ser estabelecidos e devidamente monitorados (SANTOS et al., 2005).

A carcaça suína é amplamente utilizada como matéria-prima na fabricação de produtos cárneos curados, fermentados e maturados. Não há garantias que 0 processo de obtenção desses produtos seja capaz de eliminar o risco da presença de $L$. monocytogenes. Na produção primária, o resfriamento da carcaça suína é uma etapa obrigatória. Diretrizes brasileiras e internacionais estabelecem tempo e temperaturas de resfriamento, visando o controle referente aos aspectos microbiológicos e tecnológicos da produção da carne suína. A portaria no 711/1995, do Ministério da Agricultura, Pecuária e Abastecimento, preconiza tempo mínimo de resfriamento de 12 horas, temperatura interna da câmara de $0^{\circ} \mathrm{C}$ e, ao final deste período, a carcaça deve sair para desossa com temperatura interna de, no máximo, $7^{\circ} \mathrm{C}$ (BRASIL, 1995).

O processamento adequado do suíno durante as etapas do abate interferem diretamente na obtenção de carnes seguras quanto ao aspecto de inocuidade e com boa qualidade tecnológica. As boas práticas de fabricação foram estabelecidas com intuíto de prevenir, reduzir e/ou eliminar riscos físicos, químicos e biológicos. Estas práticas abragem todos os requisitos de instalações, equipamentos, utensílios e saúde dos manipuladores (BRASIL, 1995).

Atualmente, vigoram normas específicas para 0 abate $\mathrm{e}$ processamento de suínos, como: o Regulamento de Inspeção Industrial e Sanitária de Produtos de Origem Animal - RIISPOA, Decreto n 30.691, de 26 de março de 1952 (BRASIL, 1952) e as
Normas Técnicas de Instalações e Equipamentos para Abate $e$ Industrialização de Suínos, Portaria $n^{\circ}$ 711 , de $1^{\circ}$ - de no novembro de 1995 (BRASIL, 1995).

Os programas das indústrias de alimentos de origem animal devem ser fundamentados em uma inspeção contínua e sistemática de todos os fatores que, de alguma forma, podem interferir na qualidade higiênico-sanitária dos produtos. As legislações direcionadas ao controle sanitário de alimentos tratam esses programas como requisitos básicos para garantir a inocuidade dos alimentos. Esses programas incluem 0 Procedimento Padrão de Higiene Operacional (PPHO), Programa de Análise de Perigos e Pontos Críticos de Controle (APPCC) e - Programa de Boas Práticas de Fabricação (BPF) (BRASIL, 2005).

Diretrizes do Codex Alimentarius (CAC/GL $61 \quad$ - 2007) foram estabelecidas com o objetivo de reduzir a níveis aceitáveis a probabilidade de enfermidades causadas pela presença de $L$. monocytogenes em alimentos considerados prontos para o consumo, pois só no primeiro semestre de 2012 foram publicados pela Administração de Alimentos e Medicamentos dos Estados Unidos da Américaa (Food and Drug Association -FDA) cinco recolhimentos de produtos supostamente contaminados por $L$. monocytogenes nos Estados Unidos da América.

No Brasil, não há relatos de recolhimento de produtos cárneos devido à presença de $L$. monocytogenes. Entretanto, isso não significa que não haja alimentos contaminados disponíveis para a população, já que a presença de microorganismos patogênicos, em ambientes úmidos e com baixas temperaturas pode comumente ser detectada.

Alguns países estabeleceram limites legais para o número de $L$. monocytogenes permitido em alimentos, 
especialmente para produtos prontos para o consumo, enquanto outros têm sugerido procedimentos ou critérios que não têm amparo legal (JAY, 2005).

A exemplo disso, o regulamento 1441/2007, da Comunidade Europeia, estabelece tolerância zero para $L$. monocytoges em $1 \mathrm{~g}$ de produtos carnéos (CE, 2007). As diretivas provisórias da Grã-Bretanha, estabeleceram quatro grupos de qualidades para alimentos prontos para o consumo, de acordo com o número de Listeria monocytogenes: Não detectado em $25 \mathrm{~g}$ é satisfatório; $>10^{2}$ em $25 \mathrm{~g}$ é razoavelmente satisfatório; entre $10^{2}$ a $10^{3}$ é insatisfatório, e números $>10^{3}$ tornam o produto inaceitável (GILBERT, 1992).

A França, segundo Tompkin e outros (1992), requer ausência de $L$. monocytogens em amostras de $25 \mathrm{~g}$ de alimentos para indivíduos em risco. A posição francesa parece não ser realista por esperar a ausência deste patôgeno em alimentos crus. Tem sido observado que a presença desse micro-organismo no ambiente de processamento de alimentos é inevitável, especialmente no produto pronto, consequentemente, 0 risco da contaminação do produto final pode ser reduzido, mas não eliminado.

No Brasil, não há procedimentos estabelecidos de controle de $L$. monocytogenes em produtos de origem animal prontos para o consumo ou in natura. A Instrução Normativa $n^{\circ} 09$, de 08 de abril de 2009, que regulamentava - Programa de L. monocytogenes em produtos de origem animal prontos para o consumo, foi suspensa temporariamente pelo Memorando Circular no 11/2012/CGPE/DIPOA. Por conseguinte, acredita-se que trabalhos como este possam contribuir para um delineamento de programas de controle e redução de $L$. monocytogenes na carne suína.

A determinação e quantificação da

L. monocytogenes na entrada e na saída da câmara de resfriamento de carcaças é importante para determinar a situação sanitária atual das carcaças antes e após o resfriamento e, a partir disso, propor programas de controle em pontos específicos da cadeia produtiva.

O presente estudo teve como objetivo determinar e quantificar a presença deste patógeno na carcaça suína antes e após o processo de resfriamento em câmara fria em um frigorífico do estado de Santa Catarina.

\section{MATERIAL E MÉTODOS}

O estudo foi conduzido em um frigorífico localizado no estado de Santa Catarina, entre o período de maio de 2011 até março de 2012. Para a escolha do estabelecimento foram utilizados critérios como disponibilidade em participar do projeto, registros em sistema de inspeção federal (SIF) e resfriamento das carcaças em câmara fria por um período mínimo de 12 horas. Quarenta e cinco ciclos de amostragem foram realizados no estabelecimento, acompanhando um dia de trabalho. Em cada dia, são abatidos em média 2000 animais. Em cada ciclo, foram colhidas superfícies de cinco carcaças antes do resfriamento e cinco carcaças após o resfriamento, totalizando uma amostragem de 113 carcaças antes e 113 carcaças após o resfriamento em câmara fria. $O$ número de carcaças amostradas foi determinado considerando que dados de ocorrência publicados anteriormente (Pissetti, 2012) encontram 5,5\% de carcaças positivas para $L$. monocytogenes. Considerando essa frequência, a amostragem de 113 carcaças antes e 113 carcaças após o resfriamento foram suficientes para detectar ao menos 1 (uma) carcaça positiva para $L$. monocytogenes, em um intervalo de confiança de 95\% (Thrusfield, 2004).

Foram realizadas coletas colheitas ambientais do interior da câmara fria em 

resfriamento em câmara fria

quatro pontos distintos: porta da câmara, parede, piso, e barras de proteção (ferro galvanizados), totalizando 60 amostras ambientais (15 amostras em cada ponto). Foram realizadas análises qualitativas e quantitativas quanto a Listeria sp. na área amostrada de cada carcaça e nas amostras ambientais do interior da câmara fria a análise foi apenas qualitativa. Empregou-se esponjas individuais estéreis, previamente umedecidas com um solvente constituído de 0,1\% peptona + 0,85\% $\mathrm{NaCl}$ estéril para a coleta das superfícies, tanto de carcaças como de ambiente. Nas carcaças, as esponjas foram friccionadas em quatro diferentes áreas de $100 \mathrm{~cm}^{2}$ (pernil, lombo, barriga e papada), delimitada por um molde estéril, totalizando $400 \mathrm{~cm}^{2}$ de área amostrada por carcaça, de acordo com a circular no 130/2007/CGPE/DIPOA (BRASIL, 2007). Em seguida, as quatro esponjas foram acondicionadas em sacos plásticos estéreis, representando a carcaça amostrada e transportada em caixa isotérmica ao laboratório de biotecnologia da Universidade do Oeste de Santa Catarina (UNOESC). A identificação das espécies foi realizada no laboratório de bacteriologia do Centro de Diagnóstico de Microbiologia Animal (CEDIMA), do Centro de Ciências Agroveterinárias (CAV/UDESC). Para a amostragem ambiental também foi realizada a coleta por meio de esponjas em pontos distintos delimitados em $100 \mathrm{~cm}^{2}$, as quais foram acondicionadas e transportadas ao laboratório da mesma forma que as amostras das carcaças. No laboratório, a pesquisa de Listeria spp. foi determinada utilizando-se a metodologia preconizada pela ISO 11290-1:1996/Amd.1:2004, com modificação no caldo de préenriquecimento, onde utilizou-se 0 Caldo Universidade de Vermount (UVM) no lugar do Caldo Demi-Fraser. $L$. monocytogenes ATCC 7644 foi utilizada como controle para todos os procedimentos. Para a quantificação do micro-organismo foi utilizada a técnica do Número Mais Provável (NMP), conforme descrito por Garthright, 1998. Em cada amostra adicionou-se $100 \mathrm{~mL}$ de caldo de enriquecimento para Listeria (UVM). Após homogeneização, o caldo foi transferido em alíquotas de $10 \mathrm{~mL}$ para séries de 10 tubos, foram incubados a $30^{\circ} \mathrm{C}$ por $24 \mathrm{~h}$. Alíquotas de $0,1 \mathrm{~mL}$ foram transferidas para tubos contendo caldo Fraser, que foram incubados a $36^{\circ} \mathrm{C}$ por 24-48h. A partir de cada tubo de caldo Fraser enegrecido (positivo), procedeu-se à semeadura em placas de ágares ALOA, que foram incubadas a $36^{\circ} \mathrm{C}$ por $48 \mathrm{~h}$. Uma colônia típica de cada placa foi purificada em ágar soja triptona adicionado de $0,6 \%$ de extrato de levedura (TSA-YE) e submetida aos testes de produção de catalase, de hemólise, fermentação de dextrose, xilose, ramnose e manitol e motilidade em ágar semi sólido a $25^{\circ} \mathrm{C}$. Após a confirmação das culturas do gênero Listeria, calculou-se o Número Mais Provável em $400 \mathrm{~cm}^{2}\left(\mathrm{NMP} / 400 \mathrm{~cm}^{2}\right)$ do micro-organismo, consultando-se a tabela de NMP (Garthright, 1998).

Os resultados encontrados foram analisados estatisticamente através do teste não-paramétrico qui-quadrado $\left(x^{2}\right)$, com nível de significância de 0,05 do pacote estatístico SAS (1999).

\section{RESULTADOS}

Das 226 carcaças suínas analisadas no presente trabalho apenas uma foi positiva para $L$. monocytogenes, $(0,44 \%)$ sendo isolada apenas na saída da câmara fria. O gênero Listeria $\mathrm{sp}$. foi isolado em $10,62 \%$ (12/113) das carcaças que entraram para o resfriamento em câmara fria, sendo a $L$. innocua a mais frequente. Já na saída da câmara fria 
$30,97 \%$ (35/113) das carcaças foram positivas para Listeria sp. (Tabela 01). Estatisticamente, houve diferença significativa no aumento do número de carcaças com presença de Listeria sp. na saída da câmara fria $(p=0.0002)$, em relação à entrada.

$\begin{aligned} & \text { Tabela 01- Número de carcaças positivas para diferentes espécies de Listeria na } \\
& \text { entrada e saída da câmara fria, em um frigorifico do Estado de Santa } \\
& \text { Catarina, 2011 - 2012. }\end{aligned}$
\begin{tabular}{lcc}
\hline Espécies de Listeria & Entrada da câmara fria & Saída da câmara fria \\
\hline L. innocua & $12 / 113(10,62 \%)$ & $19 / 113(16,81 \%)$ \\
L. monocytogenes & $0 / 113$ & $1 / 113(0,88 \%)$ \\
L. seeligeri & $0 / 113$ & $3 / 113(2,65 \%)$ \\
L. welshmeri & $0 / 113$ & $12 / 113(10,62 \%)$ \\
\hline Total & $12 / 113\left(10,62 \%^{\mathrm{a}}\right)$ & $35 / 113\left(30,97 \%{ }^{\circ}\right)$
\end{tabular}

$\overline{5}$ Letras diferentes na mesma linha indicam diferença estatística $(p<0,05)$.

Em relação às amostras ambientais do interior da câmara fria, observou-se frequência de 65\% (39/60) de pontos positivos somente para $L$. innocua sendo $8,33 \%(5 / 60)$ isoladas nas barras de proteção; $25 \%$ (15/60) isoladas de amostras do chão; $20 \%$ $(12 / 60)$ isoladas de amostras da parede e $11,66 \%(7 / 60)$ isoladas das amostras da porta. Para os resultados quantitativos de Listeria $\mathrm{sp}$. nas carcaças (tabela 02), não houve diferença significativa na contagem do número de Listeria $\mathrm{sp} .(\mathrm{p}=0,2829)$ nas carcaças na entrada da câmara fria em relação às carcaças na saída da câmara fria. Embora não tenha diferença significativa nesta contagem, observa-se uma tendência no aumento da contagem de Listeria sp. nas carcaças que saem da câmara fria em relação a entrada.

Tabela 02 - Quantificação de Listeria sp. das carcaças suínas na entrada e saída da câmara fria, em um estabelecimento do estado de Santa Catarina, 2011 $-2012$

\begin{tabular}{|c|c|c|}
\hline NMP de Listeria Sp. em $400 \mathrm{~cm}^{2}$ de amo stra & $\begin{array}{c}\text { Entrada } \\
\text { ( } \mathrm{n}^{\circ} \text { de carcagas) } \\
\end{array}$ & $\begin{array}{c}\text { Saída } \\
\text { ( } \mathrm{n}^{\circ} \text { de carcaças) }\end{array}$ \\
\hline$<1$ & 100 & 79 \\
\hline 1.1 & 10 & 16 \\
\hline 2.2 & 2 & 12 \\
\hline 3.6 & 0 & 2 \\
\hline 5.1 & 0 & 4 \\
\hline 6.9 & 0 & 0 \\
\hline 9.2 & 1 & 0 \\
\hline 12 & 0 & 0 \\
\hline 16 & 0 & 0 \\
\hline 23 & 0 & 0 \\
\hline$>23$ & 0 & 0 \\
\hline
\end{tabular}

\section{DISCUSSÃO}

A L. monocytogenes é um dos patógenos causadores de doenças transmitidas por alimentos. A presença em carcaças suínas demonstra o risco deste patógeno de ser transmitido ao consumidor. No presente trabalho a frequência de isolamento de $0,44 \%$, foi menor do que observado em outras regiões do Brasil: São Paulo (0,83\%) (HOFER et al., 2006), Minas Gerais $(1,66 \%)$ (SANTOS et al., 2003), Rio Grande do Sul (3,33\%) (FERRONATTO et al., 2012) e Santa Catarina (19,8\%) PISSETTI et al., 2012).

A qualidade da matéria-prima (suíno vivo), estruturas de equipamentos e instalações, boas práticas de processamento e a própria metodologia de colheita e isolamento são fatores que podem contribuir para as diferenças entre os resultados encontrados neste estudo comparando com os achados por Hofer et al., 2006; Santos et al., 2003; Ferronatto et al., 2012 e Pissetti et al., 2012.

Uma importante fonte de contaminação da linha do abate é o próprio animal vivo. Estudos realizados por Skovgaard \& Norrung (1989) encontraram $L$. monocytogenes em fezes e na pele de suínos saudáveis em frequências que podem variaram de 0 a 47\%. O patôgeno também foi detectado em raspados de tonsilas, em estudo realizado por Kanuganti et al. (2002). Yokoyama et al. (2005), colheu 250 amostras de conteúdo de ceco de suínos e isolou 29,6\% (74/250) amostras positivas para $L$. monocytogenes. A presença de suínos portadores de L. monocytogenes pode aumentar a chance da contaminação do produto final. É provavel que alimentos contaminados têm sua origem no frigorífico. Pissetti et al. (2012), sugerem que a contaminação de carcaças pelo micro-organismo ocorra a partir do extravasamento do 

resfriamento em câmara fria

conteúdo intestinal na linha de abate. Portanto, é fundamental que as etapas de liberação e oclusão do reto sejam criteriosamente monitoradas. A etapa de oclusão do reto é obrigatória, de acordo com a portaria $\mathrm{n}^{\mathrm{o}}$ 711/CGPE/DIPOA (BRASIL, 1995), e é extremamente importante para evitar o extravasamento do conteúdo fecal na carcaça, durante o seu trajeto pela linha de abate.

Por outro lado, outros estudos demonstram que há maior frequência de $L$. monocytogenes em tonsilas do que no intestino, sendo o contato dos tecidos da cabeça com a carcaça a forma de contaminação mais provável (THEVENOT et al., 2006). Contribuindo para isto, a falta de esterilização dos equipamentos e o não cumprimento do rodízio dos intrumentos (facas, serras e tesouras) a cada suíno, conforme preconizado pela portaria 711/CGPE/DIPOA (BRASIL, 1995), também são fatores que podem contribuir diretamente na contaminação cruzada durante o processo de abate. Durante as visitas para a coleta de dados, foi observado que os operários não efetuavam a troca de utensílios a cada operação. Procedimentos como esterilização dos utensílios a cada operação são essenciais para prevenir as contaminações cruzadas. A temperatura da água dos esterilizadores e o tempo de contato do utensílio com a água devem ser monitorados, caso contrário, os instrumentos poderão disseminar agentes infecciosos (BRASIL, 2005). A temperatura mínima da água dos esterilizadores deve ser superior ou igual a $82^{\circ} \mathrm{C}$ (BRASIL, 1995).

Portanto, o próprio ambiente do frigorífico oferece condições favoráveis para sobrevivência e multiplicação da $A$ L. Monocytogenes. Esta bactéria pode ser encontrada em superfícies, mesmo que estas sejam diariamente higienizadas (CARPENTIER \& CERF,
2011), devido sua característica de fácil adesão e formação de biofilme, fazendo com que o micro-organismo sobreviva a ação de desinfetantes (OLIVEIRA et al., 2010) e consequentemente permaneça no ambiente da indústria. Isto faz com que haja o risco de contaminação cruzada de alimentos durante o processamento, aumentando o risco de ocorrência de surtos (KUNIGK \& ALMEIDA, 2001).

Além de L. monocytogenes, foram isoladas outras espécies neste estudo, destacando a $L$. innocua $(10,62 \%$ 12/113) isolada na entrada da câmara fria. Embora L. innocua não seja patogênica, sua presença em ambientes industriais não deve ser subestimada; esta pode ser indicativa de presença de outras espécies, incluindo a L. monocytogenes. Vitas, Aguado e Garcia-Jabon (2004) relatam que a presença de espécies não patogênicas pode ser interpretada como indicativo de condições adequadas para a presença de outras espécies patogênicas.

Outros autores (FERRONATTO et al., 2012; SILVA et al., 2012; BARROS et al., 2007; WALSH et al., 1998) citam $L$. innocua como sendo a mais comumente encontrada em alimentos e ambiente industriais. A presença de carcaças suínas contaminadas na entrada da câmara fria, indica que está ocorrendo contaminação durante as principais etapas do abate. Faber e Peterkin (1991) descrevem que a Listeria sp. pode ser isolada de carcaças nas etapas do abate em animais sadios e/ou doentes que podem veicular esta bactéria. Por isso, as condições higiênico-sanitárias das operações devem ser garantidas por meio de procedimentos sanitários operacionais que visem minimizar as contaminações cruzadas durante as etapas de abate, por intermédio de ações preventivas no processo e no produto. 
Estatisticamente, houve diferença significativa no aumento do número de carcaças com presença de Listeria sp. na saída da câmara fria $(p=0.0002)$, em relação à entrada. $O$ aumento de $20,35 \%$ na incidência de Listeria sp. no processo de resfriamento das carcaças demonstra que este é um importante ponto do processo que deve ser observado. O caráter psicotrófico do gênero Listeria e as contaminações cruzadas no interior da câmara podem ser a resposta para o aumento de carcaças contaminadas na saída da câmara fria, comparada com a porcentagem de carcaças contaminadas na sua entrada. Mc Mullen (2000), Williams e Golden (2001) afirmam que a temperatura de refrigeração não é suficiente para controlar essa bactéria. $\mathrm{O}$ ambiente das plantas processadoras de alimentos tem recebido atenção dos pesquisadores, uma vez que ele pode contribuir para contaminação dos produtos finais por meio da contaminação cruzada (PRITCHARDT et al., 1995). Este resultado sugere contaminações cruzadas no interior da câmara fria. Essas contaminações podem surgir a partir de falhas de boas práticas de fabricação dos operadores que manipulam as carcaças no interior da câmara e/ou por água residual que, por falhas na ventilação interna, pode se tornar condensada e esta, por sua vez, goteja sobre as carcaças. O espaçamento entre as carcaças e entre as estruturas é um ponto que deve ser monitorado pelos estabelecimentos, pois ao longo do percurso realizado no interior da câmara pode ocorrer contaminação entre carcaças, as estruturas e os manipuladores..

Os resultados das amostras ambientais colhidas durante as visitas demonstram que o interior da câmara é um ambiente contaminado. $O$ estabelecimento analisado possui apenas uma câmara para resfriamento de carcaças o que dificulta operações de higienização deste local.

Conforme a portaria 711/CGPE/DIPOA (BRASIL, 1995), a carcaça deve ser resfriada por um período mínimo de 12 horas, a uma temperatura ambiente entre $-1^{\circ} \mathrm{C}$ a $1^{\circ} \mathrm{C}$; esses parâmetros fazem da câmara um ambiente favorável para o crescimento de Listeria monocytogenes. Trabalhos realizados por Gandhi e Chikindas (2007), Martinis e Franco (1998), e, Thévenot et al(2006), descrevem a temperatura próxima a $0^{\circ} \mathrm{C}$ como condição favorável para o crescimento da $L$ monocytogenes. Portanto, o procedimento de limpeza e sanitização desses estabelecimentos devem ser executado em uma frequência que garanta as condições higiênicosanitárias no interior da câmara.

Para os resultados quantitativos de Listeria sp. nas carcaças, não houve diferença significativa na contagem do número de Listeria sp. $(p=0,2829)$ nas carcaças na entrada da câmara fria em relação às carcaças na sua saída. Entretanto, observa-se uma tendência no aumento do número de carcaças com quantificação entre 1.1 - 2.2 $\mathrm{NMP} / 400 \mathrm{~cm}^{2}$. Dados sobre a população de Listeria sp. em carcaça suína são escassos. A maioria dos estudos refere-se a presença ou ausência do micro-organismo. Segundo Sakate et al. (2003) o plaqueamento direto em ágar seletivo de alíquotas do produto pode não ser eficaz pois a células de Listeria $\mathrm{sp}$. podem estar estressadas ou podem estar presentes em número pequeno, não sendo possível sua enumeração. A técnica de Número Mais Provável permite a recuperação das células estressadas $e$ a detecção do micro-organismo mesmo quando a população é baixa, entretanto, é laboriosa e de alto custo.

Nos estudos onde a população foi avaliada, os dados são bem variados. $\mathrm{Na}$ Austrália, Grau e 

resfriamento em câmara fria

Vanderlinde (1992) enumeraram $L$. monocytogenes em 130 amostras de produtos cárneos embalados a vácuo $\mathrm{e}$ encontraram populações maiores que $1000 \mathrm{UFC} / \mathrm{g}$ em sete amostras. No Brasil, um estudo realizado por Sakate et. al., (2003) encontrou em amostras de salame populações de $L$. monocytogenes que ficaram entre $<0,3$ $\mathrm{NMP} / \mathrm{g}$ - 9,2NMP/g. (séries de três tubos). Já em 2001, Schmidt encontrou L. monocytogenes em $17 \%$ das amostras de embutidos cozidos embalados à vácuo. As populações variam entre $<100 \mathrm{UFC} / \mathrm{g}$ e $200 \mathrm{UFC} / \mathrm{g}$. Embora a câmara fria não tenha aumentado ou diminuído a contagem de Listeria sp. nas carcaças, é muito importante que medidas preventivas sejam tomadas no processo (estrutura/equipamentos/operadores) e no produto antes que as carcaças possivelmente contaminadas entrem na câmara fria. A enumeração aparentemente baixa encontrada neste trabalho deve ser tratada com cautela, pois a dose infectante para causar a listeriose ainda não é conhecida e a carcaça suína sendo amplamente utilizada como matéria prima na obtenção de produtos cárneos, pode ser veículo deste patógeno ao homem.

\section{CONCLUSÃO}

Houve presença de Listeria sp. nas carcaças suínas antes e após o resfriamento em câmera fria, com aumento significativo no número de carcaças positivas após este processo. Sugerindo que a câmara fria pode ser considerado como ponto de contaminação da bactéria. Porém, com a quantificação não foi possível comprovar se houve aumento do número de Listeria sp. na carcaça suína após a câmara fria.

\section{REFERÊNCIAS}

BARROS, M. A.; NERO L.A, SILVA, L.C. et al. Listeria monocytogenes: occurrence in beef and identification of the main contamination points in processing plants. Meat Science, v.76, p.591596, 2007.

BALBANI, A. P. S., BUTUGAN, O.

Contaminação biológica de alimentos. Revista de Pediatria, v.23, n.4, p.320-328, 2001.

BAHRANI-MOUGEOT, F. K.; DONNEMBERG, M. S. Enteropathogenic bacteria in: The Desk Encyclopedia of Microbiology Amsterdam: Elsevier, 2004. 1149p

BLAIR, I.S.; DUFFY, G.; SHERIDAN, J.J.et al. Comparison of selective and nonselective media for the isolation of Listeria species from retail foods. Journal Food Safety, v.18, p 8589, 1998.

BRASIL. Circular n. 175/2005/CGPE/DIPOA. Procedimentos de Verificação dos Programas de Autocontrole (Versão Preliminar). Brasília, DF: 16 maio de 2005. Disponível em:

<http://www.abef.com.br/Legislacoes/circ17520 05.pdf $>$. Acesso em: 12/11/2012

BRASIL. Circular n. 130, de 13 de fevereiro de 2007. Exportações de carne suína para os estados-membros da União Européia. Diário Oficial da União, Brasília, DF: 13 fev. 2007.

BRASIL. Memorando Circular n. 11, de 15 de maio de 2012. Suspensão temporária das coletas de amostras do Programa de Listeria monocytogenes em produtos de origem animal prontos para o consumo - referência: Instrução Normativa ํo 09 de 08/04/2009.. Diário Oficial da União, Brasília, DF: 15 mai. 2012.

BRASIL. Portaria n. 711, de $1^{\circ}$ de novembro de 1995. Aprova as normas técnicas de instalações e equipamentos para abate e industrialização de suínos. Diário Oficial da União, Brasília, DF: 3 nov. 1995.

BRASIL .Instrução Normativa n. 09, de 08 de abril de 2009. Institui os procedimentos de controle de Listeria monocytogenes em produtos de origem animal prontos para consumos. Diário Oficial da União, Brasília, DF: 9 abr. 2009.

CAMPANINNI, M.; PEDRAZZONI, I.; BARBUTI, $\mathrm{S}$. et al. Behavior of Listeria monocytogenes during the maturation of naturally and artificially contaminated salami: effect of lactic-acid 
bacteria starter cultures. International Journal of Food Microbiology. v.20, p.169-175, 1993.

CARPENTIER, B.; CERF, O. Review Persistence of Listeria monocytogenes in food industry equipment and premises. International Journal of Food Microbiology, v.145, n.1, p.18, Jan, 2011.

CODEX ALIMENTARIUS INTERNATIONAL FOOD STANDARDS. GUIDELINES ON THE APPLICATION OF GENERAL PRINCIPLES OF FOOD HYGIENE TO THE CONTROL OF LISTERIA MONOCYTOGENES IN FOODS. CAC/GL 61/2007. Disponível em: http://www.codexalimentarius.net. Acesso em 02 out. 2012.

DEDIOL, C.; NACIF, N.J.; SÁNCHEZ, M. et al. Incidência de Listeria monocytogenes en carne Vacuna Fresca en El área Del gran Mendonza. Revista Higiene Alimentar, v.12, p.12-16,2002.

FARBER, J. M.; PETERKIN, P. I. Listeria monocytogenes: a food-borne pathogen. Microbiological Reviews, v. 55, n. 3, p. 476511, 1991.

FERRONATTO, A. I.; PELLEGRINI, D.C.P.; GUERRA, P. et al. Distribuição de grupos clonais de Listeria Monocytogenes em carcaças e no ambiente de matadouros frigoríficos de suínos. Archives of Veterinary Science v.17, n.3, p.42-49, 2012.

FENLON, D.R.; WILSON, J.; DONACHIE, W. The incidence and level of Listeria monocytogenes contamination of food sources at primary production and initial processing. Journal of Applied Bacteriology. v.81, n.6, p.641-650, 1996.

GANDHI, M.; CHIKINDAS, M.L. Listeria: A foodborne pathogen that knows how to survive. International Journal Food Microbiology, v.113, p.1-15, 2007.

GILBERT, R. J. Provissional microbiological guidelines for some ready-to-eat foods sampled at point of sale: notes for PHLS Food Examiners. Public Health Serv. Lab. n.9, p.98-99, 1992.

GRAU F.H., VANDERLINE P.B. Occurence, numbers, and growth of Listeria monocytogenes on some vacuum-packaged processed meats. Journal Food Protection. v.55, p.4-7, 1992.

GARTHRIGHT W.E. Most Probable Number from Serial Dilutions In: Bacteriological Analytical Manual - FDA 8th Ed. Revision A -
AOAC International, USA, Appendix 2, 1998. Disponível em:

http://www.fda.gov/Food/FoodScienceResearch Acesso em: 21/01/2013.

HOFER, E.; REIS, C. M. F.; HOFER, C. B. Sorovares de Listeria monocytogenes e espécies relacionadas, isoladas de material clínico humano. Revista da Sociedade Bras. de Medicina Tropical, v.39, n.1, 2006.

INTERNATIONAL LIFE SCIENCES INSTITUTE. Achieving continuous improvement in reduction in foodborne listeriosis: a risk based approach. Journal of Food Protection, v.68, p.1932 1994, 2005.

JAY, James M. Microbiologia de alimentos. 6 . ed. Porto Alegre: Artmed, p.517-542, 2005.

KANUGANTI, S. R.; WESLEY, I. V.; REDDY, P. G. et al. Detection of Listeria monocytogenes in pigs and pork. Journal of Food Protection, v.65, n.9, p.1470-1474, 2002.

KORSAK, N.; DAUBE.G.; GHAFIR, Y. et al. An efficient sampling technique used to detect four food borne pathogens on pork and beef carcasses in nine belgian abattoirs. Journal of Food Protection, v.61, p.535-541, 2005.

KUNIGK, L.; ALMEIDA, M. C. B. Action of peracetic acido $n$ Escherichia coli and Staphylococcus aureus in suspension or settled on stainless steel surfaces. Brazilian Journal of Microbiology, v.32, p.38-41, 2001.

LATHI, E. et al. Survival and detection of Escherichia coli O157:H7 and Listeria monocytogenes during the manufacture of dry sausage using two different starter cultures. Food Microbiol, v.18, p.75-85, 2001.

LECLER, C. V.; DUFOUR, B.; LOMBARD, B. et al. Pathogens in meat and milk products: surveillance and impact on human health in France. Livestock Production Science, v.76, p.195-202, 2002.

LOGUERCIO, A. P.; SILVA, W. P.; ALEIXO, J. A. G. et al. Listeria monocytogenes: um importante patógeno de origem alimentar. Rev. Higiene Alimentar, v.15, p.39-48, 2001.

LOU, Y., YOUSEF, A. E. Characteristics of Listeria monocytogenes important to food processors. In: Listeria, Listeriosis, and Food Safety, ET Ryser and EH Marth, New York: Marcel Dekker, Inc., p.131-224, 1999. 
MACGOWAN, A. P.; BOWKER, K.; MCLAUCHLIN, J. et al. The occurrence and seasonal changes in the isolation of Listeria spp. in shop bought food stuffs, human feces, sewage and soil from urban sources. Int. J. Food. Microbiol, v.21, p.325-334, 1994.

MCMULLEN, L.M. Intervention strategies to improve the safety of pork. Advances in Pork Production, n.11, p.165-173, 2000.

NiSSEN, H.; HOLCK, A. Survival of Escherichia coli O157:H7, Listeria monocytogenes and Salmonella kentucky in Norwegian fermented, dry sausage. Food Microbiology, n.15, p.273279, 1998.

OLIVEIRA, M. M. M.; BRUGNERA, D. F.; ALVES, E. et al. Biofilm formation by Listeria monocytogenes on stainless steel surface and biotransfer potential. Brazilian Journal of Microbiology, v.41, p.97-106, 2010.

PISSETTI, C.; WERLANG, G. O.; et al. Detecção de Salmonella enterica e Listeria monocytogenes em carcaças suínas na etapa de pré-resfriamento. Acta Scientiae Veterinariae, v.40, n.4, p.1071, 2012.

PRITCHARD, T. J.; FLANDERS, R. J.; DONNELY, C. W. Comparison of the incidence of Listeria on equipaments versus environmental sites within dairy processing plants. International Journal of Food Microbiology, v.26, n.3, p.375-384, 1995.

POTES, M. E. Segurança alimentar em produtos tradicionais. Rev. de Ciências Agrárias, v.30, n.1, jan. 2007.

ROCOURT, J. The genes Listeria and Listeria monocytogenes, phytogenetic, position, taxonomy and identification. Listeria, Listeriosis and Food Safety, p.1-20, 1999.

SAKATE, R. I, ARAGON, L. C., RAGHIANTE, F. et al. Quantificação de Listeria monocytogenes em salames fatiados embalados a vácuo. ALAN, v.53, n.2, 2003.

SANTOS, L. A. G.. Pesquisa de Listeria sp. em carcaças suínas como subsídio ao sistema APPCC. In: I CONGRESSO LATINOAMERICANO DE HIGIENISTAS DE ALIMENTOS, Anais... Belo Horizonte, 2003.

SAS SOFTWARE. Version 9.1. Cary, North Carolina: SAS Institute Inc., 1999.
SCHMIDT, U.; KAYA, M., Bedeutung des Vorkommens von Listerien bei Fleish und Fleischerzeugnissen. Apud: Becker B, Trierweiler B, Fechler J, Holzapfel WH. Presence of $L$. monocytogenes in samples of cooked sausages, Proceedings... Mannheim, Germany. p. 132-5, 2001.

SILVA, W. P.; LIMA, A.S.; GANDRA, E.A. et al. Listeria spp. no processamento de lingüiça frescal em frigoríficos de Pelotas, RS, Brasil. Ciência Rural, v.34, n.3, p 911-916, 2004.

SILVEIRA, E. T. F. Inovações tecnológicas aplicadas na suinocultura e suas implicações na indústria da carne. In: Ractopamina e imunocastração e seus efeito na qualidade de carcaça e carne. VI CONGRESSO BRASILEIRO DE CIÊNCIA E TECNOLOGIA DE CARNES.

Anais... São Pedro, SP, out./2011.

SKOVGAARD, N.; NORRUNG, B. The incidence of Listeria spp in feces of Danish pigs and in minced pork meat. International Journal of Food Microbiology, v.59, n.8, 1989.

SWAMINATHAN, B. et al. 2007. Listeria monocytogenes. In Doyle, M.P.; Beuchat, L.R. Food Microbiology: fundamental and frontiers. 3. ed. Washington: ASM Press, p.322-341.

THEVENOT, D.; DERBURG, A.; VERNOZYROZAND, C. An update review of Listeria monocytogenes in the pork meat industry and its products. Journal of Applied Microbiology v.01, p.7-17, 2006.

THRUSFIELD, M. V. Epidemiologia Veterinária. São Paulo: Roca, 2004.

VITAS, A. I.; AGUADO, U.; GARCIA-JALON, I. Occurence of Listeria monocytogenes in fresh and processed foods in Navarro (Spain). International Journal of Food Microbiology, v.90, n.30, p.349-356, 2004.

YOKOYAMA, E.; SAITOH, T.; MARUYAMA, S.; KATSUBE, Y. The marked increase of Listeria monocytogenes isolation from contents of swine cecum. Comparative Immunology

Microbiology \& Infectious Diseases, v.28, n.4, p. 259-268, Jul, 2005.

\section{UNITED STATE FOOD AND DRUG} ADMINISTRATION; UNITED STATE FOOD SAFETY AND INSPECTION SERVICE. 2003. Quantitative assessment of relative risk to public health from foodborne Listeria monocytogenes among selected categories of ready-to-eat foods. Available in Docket n. 1999, v. 23-28. 
Disponível em:

<http://www.fda.gov/downloads/food/ >. Acesso

em: 15 dez. 2012

UNITED STATES DEPARTMENT OF

AGRICULTURE. Food Safety Inspection

Service, 2001. Disponível em:

<http://www.fsis.usda.gov/FACTSheets/Food_S

afety_Security_Consumers/index.asp $>$. Acesso

em: 31 nov. 2012.

WALSH, D. et al. Comparison of selective and non selective media for the isolation of Listeria species from retail foods. Journal Food Safety, v.18, p.85-89, 1998.

WILLIAMS, R. C.; GOLDEN, D.A. Influence of modified atmospheric store, lactic acid, and $\mathrm{NaCL}$ on survival of sublethally heat-injured Listeria monocytogenes. International Journal of Food Microbiology, v.64, n.3, p.379-389, 2001.

WORLD HEALTH ORGANIZATION. Food safety and foodborne illness. 2007. Disponível em:

<http://www.who.int/mediacentre/factsheets/fs23 7/en/print.html>. Acesso em: 12 ago. 2009. 